\title{
Massive Subcutaneous Emphysema and Pneumomediastinum Following Endotracheal Intubation
}

\author{
Akihiro Sakamoto, Youichirou Kogou, Nobuhiro Matsumoto and Masamitsu Nakazato
}

Key words: subcutaneous emphysema, intubation

(Intern Med 52: 1759, 2013)

(DOI: 10.2169/internalmedicine.52.0575)
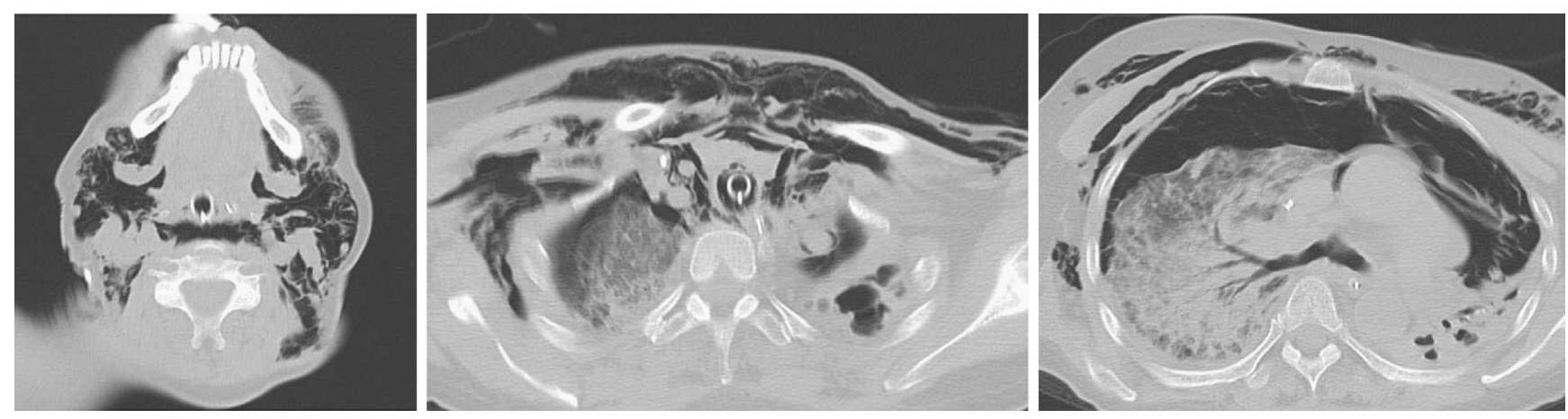

Picture.

A 66-year-old woman with subclinical pulmonary tuberculosis sequelae was admitted to our hospital due to fever, coughing and dyspnea. She underwent immediate oral intubation with an endotracheal tube and was placed on a ventilator due to severe hypoxia. Several hours after intubation, extensive swelling developed in the cervical region and anterior chest wall. Chest computed tomography revealed massive subcutaneous emphysema and a pneumomediastinum (Picture). We treated the patient conservatively, and the emphysema completely resolved several days later. She was diagnosed with pneumocystis pneumonia that was considered to have been the cause of her presenting symptoms. After treatment, she was discharged uneventfully.

Subcutaneous emphysema with a pneumomediastinum is a common clinical manifestation of rare tracheal injury fol- lowing intubation (1). Repeated attempts to perform a difficult intubation, allegedly one of the most common factors contributing to postintubation tracheal injury (2), was considered to be the possible cause of injury in the present case.

The authors state that they have no Conflict of Interest (COI).

\section{References}

1. Medina CR, Camargo Jde J, Felicetti JC, Machuca TN, Gomes Bde M, Melo IA. Post-intubation tracheal injury: report of three cases and literature review. J Bras Pneumol 35: 809-813, 2009.

2. Conti M, Pougeoise M, Wurtz A, et al. Management of postintubation tracheobronchial ruptures. Chest 130: 412-418, 2006.

Neurology, Respirology, Endocrinology, and Metabolism, Department of Internal Medicine, Faculty of Medicine, University of Miyazaki, Japan Received for publication March 14, 2013; Accepted for publication March 31, 2013

Correspondence to Dr. Akihiro Sakamoto, as-nz@hotmail.co.jp

(C) 2013 The Japanese Society of Internal Medicine Journal Website: http://www.naika.or.jp/imonline/index.html 